\title{
Acute Diffuse Glomerulonephritis
}

National Cancer Institute

\section{Source}

National Cancer Institute. Acute Diffuse Glomerulonephritis. NCI Thesaurus. Code C35587.

An acute inflammation of the glomeruli, in which all glomeruli are affected, resulting in acute renal failure. 